\title{
(6) OPEN ACCESS \\ Relative efficacy and safety of topical non-steroidal anti-inflammatory drugs for osteoarthritis: a systematic review and network meta-analysis of randomised controlled trials and observational studies
}

\author{
Chao Zeng, ${ }^{1,2}$ Jie Wei, ${ }^{2,3}$ Monica S M Persson, ${ }^{4,5}$ Aliya Sarmanova, ${ }^{4,5}$ \\ Michael Doherty, ${ }_{1}^{4,5}$ Dongxing Xie, ${ }^{1}$ YiLun Wang, ${ }^{1}$ Xiaoxiao Li, ${ }^{6}$ Jiatian Li, ${ }^{1}$ \\ Huizhong Long, ${ }^{1}$ Guanghua Lei, ${ }^{1,6,7,8}$ Weiya Zhang ${ }^{4,5}$
}

- Additional material is published online only. To view please visit the journal online (http://dx.doi.org/10.1136/ bjsports-2017-098043).

For numbered affiliations see end of article.

Correspondence to Dr Guanghua Lei, Department of Orthopaedics, Xiangya Hospital, Central South University, Changsha, Hunan, China; lei_guanghua@csu.edu.cn and Professor Weiya Zhang, Academic Rheumatology, Clinical Sciences Building, University of Nottingham, City Hospital, Nottingham, UK: weiya.zhang@nottingham.ac.uk

CZ and JW contributed equally. $\mathrm{GL}$ and WZ contributed equally.

Accepted 22 December 2017 Published Online First 7 February 2018
Check for updates

\section{To cite: Zeng $C$}

Wei J, Persson MSM,

et al. Br J Sports Med

2018:52:642-650.

\section{ABSTRACT}

Objectives To compare the efficacy and safety of topical non-steroidal anti-inflammatory drugs (NSAIDs), including salicylate, for the treatment of osteoarthritis (OA).

Methods PubMed, Embase, Cochrane Library and Web of Science were searched from 1966 to January 2017. Randomised controlled trials (RCTs) comparing topical NSAIDs with placebo or each other in patients with OA and observational studies comparing topical NSAIDs with no treatment or each other irrespective of disease were included. Two investigators identified studies and independently extracted data. Bayesian network and conventional meta-analyses were conducted. The primary outcomes were pain relief for RCTs and risk of adverse effects (AEs) for observational studies.

Results 43 studies, comprising 36 RCTs (7 900 patients with OA) and seven observational studies (218074 participants), were included. Overall, topical NSAIDs were superior to placebo for relieving pain (standardised mean difference $(\mathrm{SMD})=-0.30,95 \% \mathrm{Cl}-0.40$ to -0.20$)$ and improving function $(S M D=-0.35,95 \% \mathrm{Cl}-0.45$ to $-0.24)$ in OA. Of all topical NSAIDs, diclofenac patches were most effective for $\mathrm{OA}$ pain $(S M D=-0.81,95 \% \mathrm{Cl}$ -1.12 to -0.52$)$ and piroxicam was most effective for functional improvement $(S M D=-1.04,95 \% \mathrm{Cl}-1.60$ to -0.48 ) compared with placebo. Although salicylate gel was associated with higher withdrawal rates due to AEs, the remaining topical NSAIDs were not associated with any increased local or systemic AEs.

Conclusions Topical NSAIDs were effective and safe for OA. Diclofenac patches may be the most effective topical NSAID for pain relief. No serious gastrointestinal and renal AEs were observed in trials or the general population. However, confirmation of the cardiovascular safety of topical NSAIDs still warrants further observational study.

\section{INTRODUCTION}

Osteoarthritis (OA) is a major source of pain, disability and socioeconomic costs worldwide $^{1}$ and commonly affects footballers, rugby players and other athletes. ${ }^{2-4}$ Oral non-steroidal anti-inflammatory drugs (NSAIDs) are recommended for OA pain, ${ }^{5-10}$ but their safety concerns often outweigh their benefits. ${ }^{11}$ Concerns over the gastrointestinal (GI) risk of oral traditional NSAIDs are widely accepted, ${ }^{12}$ and selective cyclooxygenase-2 (COX-2) inhibitors were developed as an alternative to reduce this risk. COX-2 inhibitors, however, are associated with an increased risk of cardiovascular (CV) events. ${ }^{13-17}$ It is therefore suggested that both oral NSAIDs and COX-2 inhibitors should be prescribed with a proton pump inhibitor in patients with a high risk of GI bleeding. ${ }^{18-20}$ However, the issues associated with polypharmacy and the additional costs of this combination therapy limit their use. $^{21}$

Topical NSAIDs offer an alternative to decrease the risk of systemic NSAIDs. ${ }^{22}$ Although topical NSAIDs are considered relatively safe, their skin adverse effects (AEs) cannot be ignored (ranging from $10 \%$ to $39 \%) .^{23} 24$ With respect to systemic AEs, GI bleeding, dyspepsia, acute renal impairment and asthma have been reported in relation to topical NSAIDs. ${ }^{25-27}$ Furthermore, the prevalence of systemic AEs in the older population has been reported to be as high as $17.5 \%$, of which 2\%-9\% may be GI AEs. ${ }^{24}$ However, these studies did not have control groups and the risk cannot be wholly attributed to the use of topical NSAIDs. Therefore, the safety profile of topical NSAIDs remains unclear.

The Osteoarthritis Research Society International guidelines consider topical NSAIDs to be safer and better tolerated than oral NSAIDs in knee OA. ${ }^{6}$ In UK, the National Institute for Health and Care Excellence (NICE) recommend topical NSAIDs ahead of systemic analgesics (ie, paracetamol, oral NSAIDs, COX-2 inhibitors and opioids) for knee and hand OA. ${ }^{5}$ In 2004, we conducted a conventional meta-analysis and found that topical NSAIDs were effective for OA pain, but the efficacy only remained significant in the first 2 weeks of application when compared with placebo. ${ }^{28}$ Due to the limited number of trials (13) included at the time, the results may not be conclusive. More recently, a meta-analysis of 215 trials reported that topical NSAIDs exhibited the largest overall treatment effect (ie, specific treatment effect plus contextual effect) for pain relief in OA among 11 
representative treatments, including complementary, pharmacological, non-pharmacological and surgical treatments. ${ }^{29}$ Although recommended and known to be effective, it is still a challenge to choose a particular topical NSAID when faced with so many available options that vary in terms of the contained NSAID, carrier and mode of application (eg, cream, gel and patch).

A recent Cochrane systematic review examined the efficacy and safety of topical NSAIDs in chronic musculoskeletal pain. ${ }^{30}$ However, it was not specific to OA and could not compare the relative efficacy between topical NSAIDs as it was not a network meta-analysis. Furthermore, it used only randomised controlled trials (RCTs) for safety assessment. RCTs are only relevant for AEs with a high incidence, while observational studies are required for AEs that occur with moderate-low incidence and that require longer term to occur.

We undertook this systematic review and network meta-analysis of RCTs and observational studies and have ranked the topical NSAIDs (including salicylate) based on the results.

\section{METHODS}

\section{Literature search}

Systematic literature searches were undertaken using PubMed, Embase, Cochrane Library and Web of Science. Search strategies, using a series of keywords related to topical NSAIDs (including salicylate), formulations and study designs, were used to identify relevant RCTs in patients with OA and relevant observational studies in any condition (online supplementary appendix 1) from 1966 to January 2017. The database search was supplemented by subsequent periodic scrutiny of unpublished and ongoing RCTs from the WHO International Clinical Trials Registry (ICTRP) (http://apps.who.int/trialsearch/). In addition, references of the retrieved papers and reviews were manually reviewed.

\section{Inclusion/exclusion criteria}

The inclusion criteria for RCTs were as follows: (1) RCTs; (2) studies on patients with OA at any joint; (3) studies comparing topical NSAIDs (including salicylate) with placebo or each other; (4) studies reporting pain, function or AE outcomes in patients and (5) studies published in any language. The following studies were excluded: (1) secondary analyses, including some combined data analyses of published RCTs; (2) studies where the follow-up time was less than 1 week; (3) cross-over design studies; (4) topical NSAIDs combined with other drugs; (5) studies for postoperative pain and (6) abstract only (insufficient data).

The inclusion criteria for observational studies were as follows: (1) observational studies (case-control, nested case-control, cross-sectional, cohort or longitudinal studies); (2) studies comparing topical NSAIDs (including salicylate) with no treatment or each other; (3) studies reporting any AE outcomes in humans and (4) studies published in any language. The following studies were excluded: (1) ophthalmological conditions and (2) abstract only.

\section{Quality assessment}

The Cochrane risk of the bias assessment tool was used to determine the methodological quality of RCTs. ${ }^{31} \mathrm{~A}$ total of six domains were evaluated: random sequence generation, allocation concealment, participant blinding, outcome assessor blinding, incomplete outcome data and selective reporting. Each domain was assigned a judgement of low risk of bias, high risk of bias or unclear risk of bias. The judgments for each domain were made strictly following the Cochrane Handbook V.5.1.0, Chapter 8.5. ${ }^{31}$

The methodological quality of the observational studies was evaluated using the Newcastle-Ottawa Scale (NOS), ${ }^{32}$ which was developed to assess the quality of non-randomised studies based on three broad domains: selection of the study groups, comparability among different groups and ascertainment of either the exposure or outcome of interest. The total score of NOS ranges from 0 to 9 based on its assessment items.

\section{Outcome measures}

For RCTs, the primary outcome was pain relief. The secondary outcome was functional improvement. The change-from-baseline score at the last follow-up period was used/calculated. If a study reported multiple pain scales, the scale with the highest sensitivity to change was used. ${ }^{33}$ The function subscale of Western Ontario and McMaster Universities Arthritis Index (WOMAC) was used for the assessment of functional improvement. If a study did not measure or report WOMAC function, the Lequesne Index or one of the other functional measurement scales was used instead. If the original paper was unavailable/ unpublished, the outcomes were extracted from systematic reviews and meta-analyses, if available. ${ }^{30}$ If a study involved multiple treatment groups with different doses of the same drug, the data were combined into one treatment group. Only differences between two treatment arms were calculated. As different scales were used for the same outcome, the standardised mean difference (SMD) was calculated. ${ }^{31}$

To determine the safety and tolerability of topical NSAIDs, data from both RCTs and observational studies were analysed separately. The number of participants who experienced any $\mathrm{AE}$ (including local, GI, CV and renal AEs) and withdrawals due to AEs were calculated per group. The adjusted OR for any AE was derived for the safety of topical NSAIDs versus placebo/control. If unavailable, the crude OR was selected instead.

\section{Statistical analysis}

A conventional meta-analysis was conducted to compare topical NSAIDs overall with placebo (in RCTs) and with no treatment (in observational studies). The heterogeneity of the effect size across the studies was tested using the $\mathrm{Q}$ statistic $(\mathrm{P}<0.05$ was considered heterogeneous) and $\mathrm{I}^{2}$ statistic $\left(\mathrm{I}^{2}>50 \%\right.$ was considered heterogeneous). If there was significant heterogeneity between studies, a random-effects model was used; otherwise, a fixed-effects model was used. Subgroup analyses of topical NSAIDs versus placebo at different follow-up periods (week 1 to week 4 and over 4 weeks) were conducted.

The Bayesian network meta-analysis methods have been described in our previous research. ${ }^{15163435}$ The methods used can increase the number of studies within each comparison, thereby narrowing the width of the CI of the estimate. ${ }^{36-40}$ The Markov Chain Monte Carlo method was used to estimate posterior densities for unknown variables. ${ }^{39} 4142 \mathrm{~A}$ random effects model was adopted as the most appropriate and conservative analysis method to assess differences between trials. Two Markov chains ran simultaneously with different initial values, which were chosen arbitrarily for convergence. A total of 50000 simulations were generated for each of the two sets of initial values, and the first 10000 simulations were discarded due to the burn-in period. The WinBUGS codes are available at http://www.bristol. ac.uk/social-community-medicine/projects/mpes/ (online supplementary appendix 2). The overall effect sizes (SMDs or ORs) were generated from the median of the posterior distribution. 


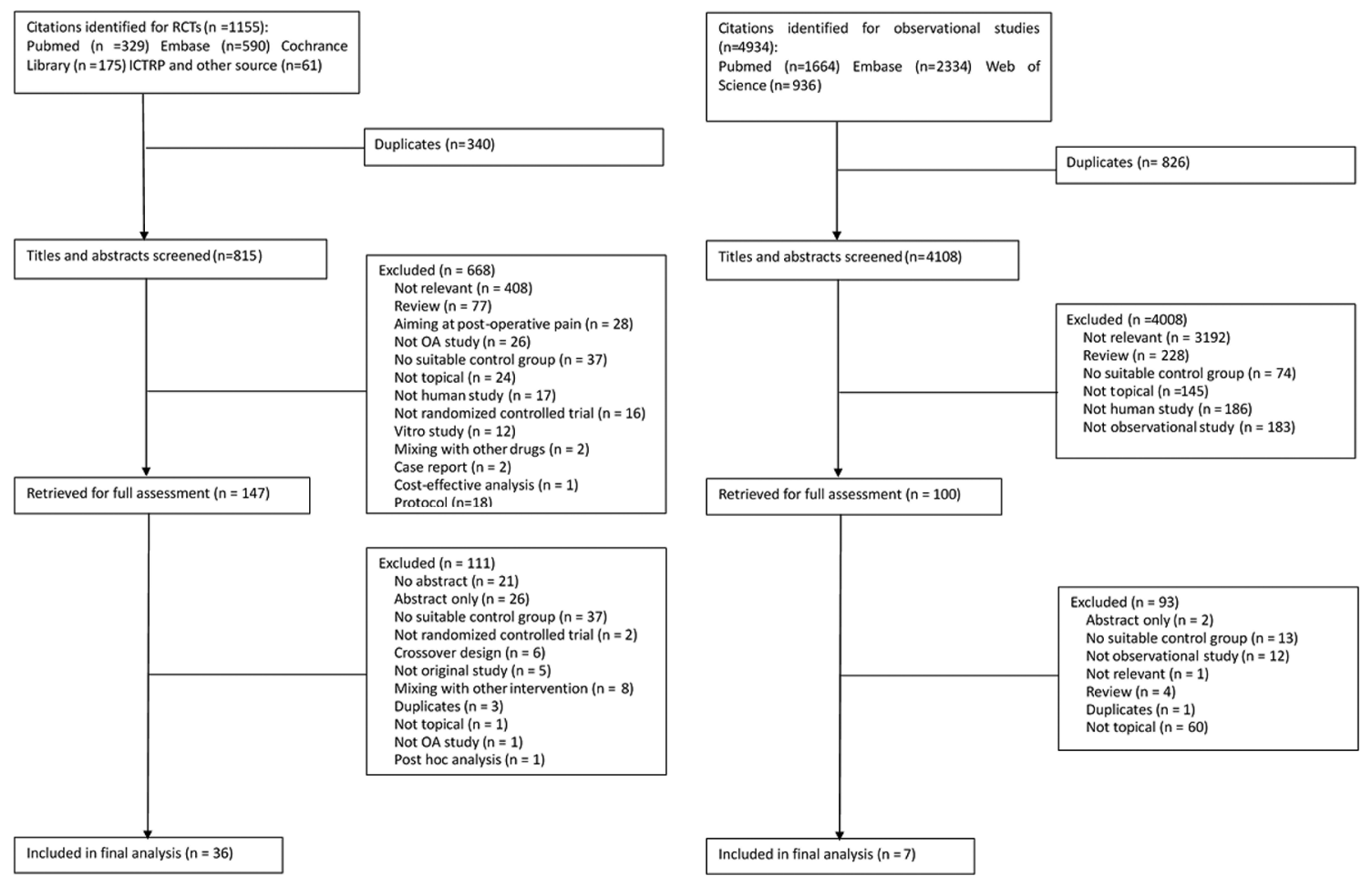

Figure 1 Study selection process. ICTRP, International Clinical Trials Registry; OA, osteoarthritis; RCT, randomised controlled trials.

The 2.5th and 97.5th percentiles of the posterior distribution were considered the lower and upper limit, respectively, of the traditional corresponding 95\% CI. Significant differences were identified when the $95 \%$ CI did not include 0 for SMD or 1 for OR. Heterogeneity was defined as the variability of results across trials, with $\tau^{2}<0.04$ indicating a low level and $\tau^{2}>0.4$ a high level. $^{43}$ When trials contained three or more treatment arms, inconsistency was defined by the differences between direct and indirect effect estimates for the same comparison. ${ }^{44}$ The fit of the model to the data was measured by calculating the posterior mean residual deviance. ${ }^{45}$ Rankings for all evaluated treatments were based on the level of effect according to their posterior probabilities. Surface under the cumulative ranking (SUCRA) is equal to $100 \%$ for the best treatment and $0 \%$ for the worst treatment. ${ }^{446}$ Subgroup analyses were conducted by restricting studies to only those who enrolled knee OA or hand OA participants, to non-commercially funded studies and to studies with efficacy data at 1 or 2 weeks. Network meta-regressions were conducted to consider the potential impact of pain and function level at baseline, length of follow-up time and treatment duration. ${ }^{47-49}$

All statistical analyses were conducted using WinBUGS software (V.1.4.3, MRC Biostatistics Unit, Cambridge, UK), STATA software (V.11.0, Stata, College Station, Texas, USA) and Review Manager 5.3 software (RevMan 5.3, The Cochrane Collaboration, Oxford, UK).

\section{RESULTS}

\section{Study selection and characteristics of the included studies}

Forty-three studies, comprising 36 RCTs (7900 patients with OA) and 7 observational studies (218074 participants), were included. Figure 1 depicts the details of the selection process. Twelve topical therapies (ibuprofen, diclofenac patch, diclofenac gel, diclofenac solution, ketoprofen, eltenac, nimesulide, indomethacin, etoricoxib, piroxicam, salicylate and placebo) were evaluated for OA in the included RCTs (figure 2). The characteristics of the included comparisons are shown in table 1 and detailed information on the included RCTs and observational studies is shown in online supplementary appendix 3 . The methodological quality was evaluated for all included trials and observational studies (online supplementary appendix 4).

\section{Effects on pain relief in RCTs (vs placebo at last follow-up point)}

A total of 29 trials involving all 12 topical therapies were analysed.

\section{Conventional meta-analysis}

Topical NSAIDs overall were superior to placebo for pain relief $(\mathrm{SMD}=-0.30,95 \% \mathrm{CI}-0.40$ to -0.20$)$ (online supplementary appendix 5). Subgroup analysis further indicated that statistically significant differences were evident at weeks 1, 2, 3, 4 and over 4 weeks (online supplementary appendix 5). Diclofenac patch exhibited the largest effect for pain relief $(\mathrm{SMD}=-0.94$, $95 \% \mathrm{CI}-1.20$ to -0.68 ) (table 1 ).

\section{Network meta-analysis}

Diclofenac patch was most effective for pain relief $(\mathrm{SMD}=-0.81$, $95 \%$ CI -1.12 to -0.52 ) (figure 3 ). The detailed results are illustrated in table 2 and the rankings based on SUCRA are shown in online supplementary appendix 6. Diclofenac patch had the largest probability of being the best treatment option (SUCRA=95.7\%), followed by ibuprofen cream (SUCRA $=88.81 \%)$. Network meta-regression showed that there were no significant interactions between pain relief and baseline pain level or length of follow-up time (online supplementary appendix 7). There was no evidence of high heterogeneity among the trials $\left(\tau^{2}=0.01\right)$. Evaluation of the goodness of fit demonstrated a good fit with a posterior mean residual 


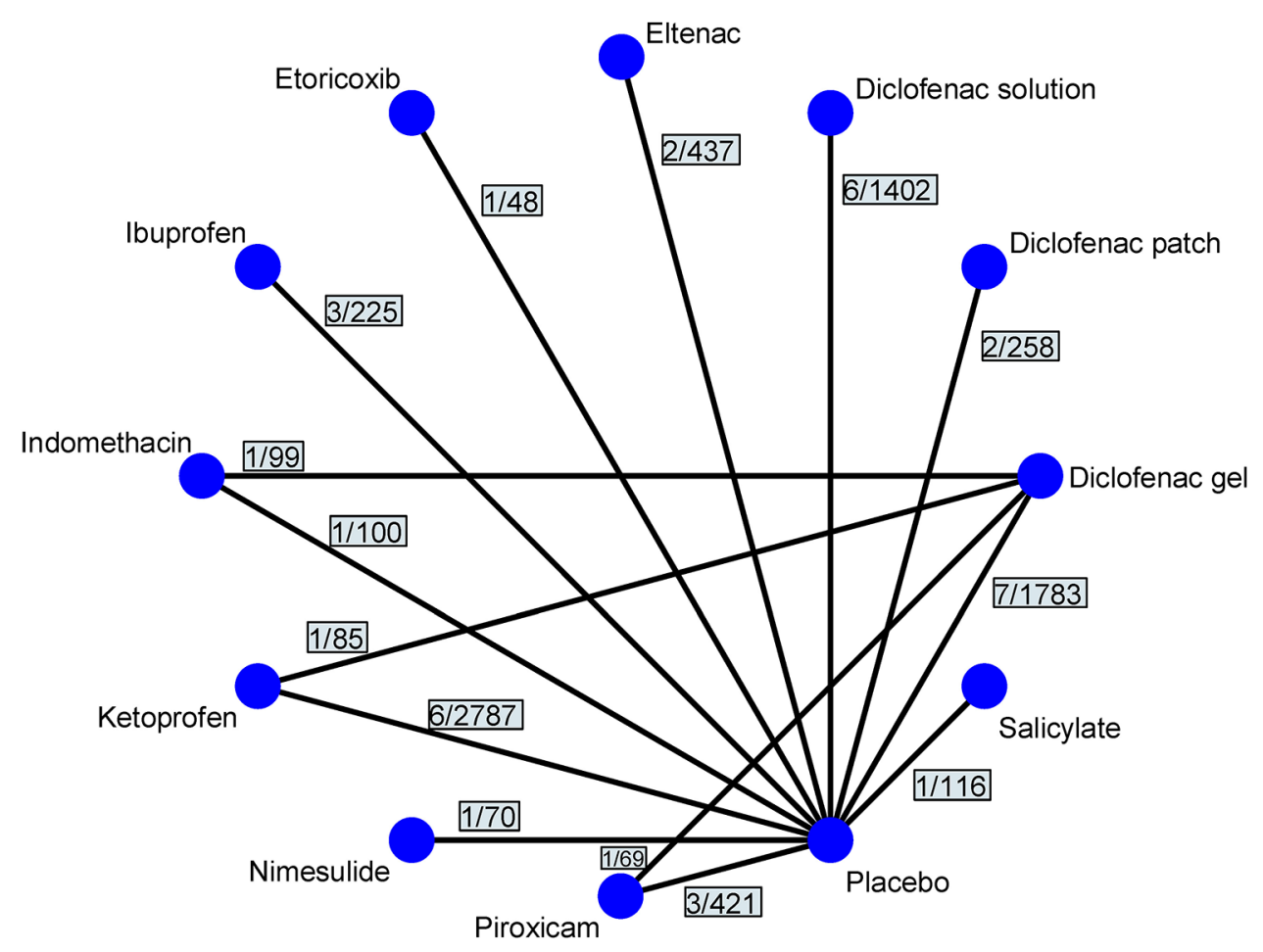

Figure 2 Structure of network formed by interventions. The lines between treatment nodes indicate the direct comparisons made within randomised controlled trials. Numbers $(n / n)$ near the line indicate 'number of trials/number of participants' of the related comparisons.

deviance of 61.31 (58 data points). Subgroup analysis of studies with patients with knee $\mathrm{OA}$ and studies with efficacy data at 1 or 2 weeks did not reveal any substantial change (online supplementary appendix 8). Only one trial ${ }^{50}$ investigated the effects of topical diclofenac gel on patients with hand $\mathrm{OA}(\mathrm{SMD}=-0.20$, $95 \% \mathrm{C}$ : -0.40 to 0.00$)$. After excluding commercially funded/ sponsored trials (17 trials), only diclofenac patch was statistically superior to placebo for pain relief $(\mathrm{SMD}=-0.82,95 \% \mathrm{CI}-1.65$ to -0.03 ) (online supplementary appendix 8 ).

\section{Effects on functional improvement in RCTs (vs placebo at last follow-up point)}

A total of 27 trials involving 11 topical therapies (all except salicylate) were analysed.

\section{Conventional meta-analysis}

Topical NSAIDs overall had a significantly better effect than placebo $(\mathrm{SMD}=-0.35,95 \% \mathrm{CI}-0.45$ to -0.24$)$ (online supplementary appendix 5). Subgroup analysis further indicated that significant differences were evident at weeks 1, 2, 3, 4 and over 4 weeks (online supplementary appendix 5). Piroxicam $(\mathrm{SMD}=-1.07,95 \% \mathrm{CI}-1.40$ to -0.74$)$ exhibited the largest effect for functional improvement (table 1).

\section{Network meta-analysis}

Piroxicam was the best treatment for functional improvement $(\mathrm{SMD}=-1.04,95 \% \mathrm{CI}-1.60$ to -0.48$)$ (figure 3 ). The detailed results are illustrated in table 2 . The ranking based on SUCRA is shown in online supplementary appendix 6 . Piroxicam had the largest probability of being the best treatment option (SUCRA=95.6\%), followed by ibuprofen cream
$($ SUCRA $=84.4 \%)$ and diclofenac patch (SUCRA $=72.6 \%)$. Network meta-regression showed no significant interactions between functional improvement and baseline function level or length of follow-up (online supplementary appendix 7). There was no evidence of high heterogeneity among trials $\left(\tau^{2}=0.05\right)$. Evaluation of the goodness of fit demonstrated a good fit with a posterior mean residual deviance of 58.12 (54 data points). Subgroup analysis of knee OA studies and studies with efficacy data at 1 or 2 weeks did not reveal any substantial change (online supplementary appendix 8). Only one trial ${ }^{50}$ on diclofenac gel was restricted to patients with hand $\mathrm{OA}(\mathrm{SMD}=-0.26,95 \% \mathrm{CI}$ -0.46 to -0.06$)$. After excluding the trials funded/sponsored by commercial companies (16 trials), no active treatment was superior to placebo for functional improvement (online supplementary appendix 8).

Adverse effects in RCTs (vs placebo at last follow-up point) A total of 31 trials involving 11 topical therapies (all except etoricoxib) reported AEs.

\section{Conventional meta-analysis}

Topical NSAID s overall did not show a significantly higher risk for skin (OR=1.38, 95\% CI 0.99 to 1.92), GI or CV AEs (online supplementary appendix 5). However, the withdrawal rate due to AE was significantly higher $(\mathrm{OR}=1.56,95 \% \mathrm{CI} 1.21$ to 2.00$)$.

Network meta-analysis

Apart from salicylate gel $(\mathrm{OR}=16.83$, 95\% CI 2.12 to 499.3$)$ which had greater withdrawal due to AE rates compared with placebo, topical NSAIDs had neither more withdrawals due to $\mathrm{AE}$ nor higher incidence of AEs (such as skin, GI and CV events) 
Table 1 Characteristics of the included comparisons in RCTs and the results of conventional meta-analysis

\begin{tabular}{|c|c|c|c|c|c|c|c|c|}
\hline Comparison & No. of trials & No. of pts & Target joint & $\begin{array}{l}\text { Mean age } \\
\text { (range) }\end{array}$ & Female $\%$ & $\begin{array}{l}\text { Mean FU periods } \\
\text { (weeks, range) }\end{array}$ & $\begin{array}{l}\text { SMD }(95 \% \mathrm{CI}) \\
\text { for pain }\end{array}$ & $\begin{array}{l}\text { SMD }(95 \% \mathrm{CI}) \\
\text { for function }\end{array}$ \\
\hline $\begin{array}{l}\text { Diclofenac patch vs } \\
\text { placebo }\end{array}$ & 2 & 258 & Knee & $65.2(64-67)$ & 69.8 & 2 & $\begin{array}{l}-0.94 \\
(-1.20 \text { to }-0.68)\end{array}$ & $\begin{array}{l}-0.55 \\
(-0.81 \text { to }-0.30)\end{array}$ \\
\hline Ibuprofen vs placebo & 3 & 225 & Knee & $63.9(60.8-67)$ & 63.5 & $1.3(1-2)$ & $\begin{array}{l}-0.66 \\
(-1.06 \text { to }-0.25)\end{array}$ & $\begin{array}{l}-0.72 \\
(-1.00 \text { to }-0.44)\end{array}$ \\
\hline Piroxicam vs placebo & 3 & 421 & Knee or lumbar & 51 & 64.5 & 2 & $\begin{array}{l}-0.50 \\
(-0.82 \text { to }-0.19)\end{array}$ & $\begin{array}{l}-1.07 \\
(-1.40 \text { to }-0.74)\end{array}$ \\
\hline Nimesulide vs placebo & 1 & 70 & Knee & 53.6 & 84.3 & 4 & $\begin{array}{l}-0.39 \\
(-0.90 \text { to } 0.13)\end{array}$ & $\begin{array}{l}-0.49 \\
(-1.01 \text { to } 0.03)\end{array}$ \\
\hline $\begin{array}{l}\text { Diclofenac gel vs } \\
\text { placebo }\end{array}$ & 7 & 1783 & Multiple joints & $61.3(52-67)$ & 69.2 & $6(2-12)$ & $\begin{array}{l}-0.30 \\
(-0.39 \text { to }-0.20)\end{array}$ & $\begin{array}{l}-0.36 \\
(-0.46 \text { to }-0.27)\end{array}$ \\
\hline $\begin{array}{l}\text { Diclofenac solution vs } \\
\text { placebo }\end{array}$ & 6 & 1402 & Knee & $62.8(60.2-65)$ & 63.8 & $7.3(4-12)$ & $\begin{array}{l}-0.29 \\
(-0.40 \text { to }-0.18)\end{array}$ & $\begin{array}{l}-0.32 \\
(-0.43 \text { to }-0.21)\end{array}$ \\
\hline Ketoprofen vs placebo & 6 & 2787 & Knee & $61.5(59-63.3)$ & 67.9 & $8(2-12)$ & $\begin{array}{l}-0.10 \\
(-0.30 \text { to } 0.11)\end{array}$ & $\begin{array}{l}-0.04 \\
(-0.12 \text { to } 0.05)\end{array}$ \\
\hline Salicylate vs placebo & 1 & 116 & Knee or hip & 65.7 & 55.2 & 4 & $\begin{array}{l}-0.08 \\
(-0.45 \text { to } 0.29)\end{array}$ & NR \\
\hline Eltenac vs placebo & 2 & 437 & Knee & $64.5(61-67)$ & 72.3 & 4 & $\begin{array}{l}-0.02 \\
(-0.23 \text { to } 0.18)\end{array}$ & $\begin{array}{l}-0.37 \\
(-0.58 \text { to }-0.17)\end{array}$ \\
\hline Etoricoxib vs placebo & 1 & 48 & Knee & 61.4 & 68.8 & 4 & $\begin{array}{l}0.04 \\
(-0.53 \text { to } 0.60)\end{array}$ & $\begin{array}{l}0.13 \\
(-0.44 \text { to } 0.69)\end{array}$ \\
\hline $\begin{array}{l}\text { Indomethacin vs } \\
\text { diclofenac gel }\end{array}$ & 1 & 99 & Knee, hip or hand & 54.2 & 68.7 & 2 & $\begin{array}{l}0.29 \\
(-0.11 \text { to } 0.69)\end{array}$ & $\begin{array}{l}0.38 \\
(-0.03 \text { to } 0.78)\end{array}$ \\
\hline $\begin{array}{l}\text { Indomethacin vs } \\
\text { placebo }\end{array}$ & 1 & 100 & Knee or ankle & NR & 72 & 2 & NR & NR \\
\hline $\begin{array}{l}\text { Ketoprofen vs } \\
\text { diclofenac gel }\end{array}$ & 1 & 85 & Knee & 57.1 & 84.7 & 4 & NR & $\begin{array}{l}-0.13 \\
(-1.48 \text { to }-0.58)\end{array}$ \\
\hline $\begin{array}{l}\text { Piroxicam vs } \\
\text { diclofenac gel }\end{array}$ & 1 & 69 & Knee & 56.5 & 60.9 & 4 & NR & NR \\
\hline
\end{tabular}

FU, follow-up; No. of pts, number of participants included; No. of trials, number of trials included; NR, not reported; RCTs, randomised controlled trials; SMD, standardised mean difference.

(table 3). The relative safety between different topical NSAIDs can be seen in online supplementary appendix 8 . The network meta-regression showed that there was no significant interaction between treatment duration and AEs (online supplementary appendix 7). Only one $\mathrm{RCT}^{51}$ reported the risk of renal AEs and the results showed no significant risk of renal or urinary disorders associated with the use of topical ketoprofen (100, 50 or $25 \mathrm{mg}$ ).

\section{Adverse effects in observational studies}

A total of seven observational studies ${ }^{52-58}$ reported AEs of topical NSAIDs. Conventional meta-analysis showed that topical NSAID users did not exhibit a significantly higher rate of AEs than non-users $(\mathrm{OR}=1.19,95 \% \mathrm{CI} 0.92$ to 1.55$)$ (online supplementary appendix 5). Three (online supplementary file 1) case-control studies (including a nested case-control study) ${ }^{52-54}$ examined serious systemic AEs such as GI bleeding, perforation, symptomatic peptic ulcers and acute renal failure associated with the use of topical NSAIDs. The risks of GI bleeding $(\mathrm{OR}=1.45$, $95 \% \mathrm{CI} 0.84$ to 2.50$)$, acute renal failure $(\mathrm{OR}=1.33,95 \% \mathrm{CI}$ 0.79 to 2.24$)$ and symptomatic peptic ulcers $(\mathrm{OR}=1.00,95 \% \mathrm{CI}$ 0.60 to 1.70 ) were not significant. In addition, two case-control studies ${ }^{55} 56$ examined the photosensitivity associated with topical NSAIDs. One $\mathrm{e}^{55}$ showed that the reporting OR for topical ketoprofen was 3.9 (95\% CI 2.4 to 6.4$)$ and the proportional reporting ratio was 3.4 (95\% CI 2.1 to 5.5 ), versus other topical NSAIDs. The other ${ }^{56}$ reported that the overall population attributable risk (PAR) for severe photosensitivity reactions linked to topical ketoprofen was $11.92 \%(-0.12$ to 52.99$)$ and the PAR for other topical NSAIDs was $2.47 \%$ (-3.17 to 29.99). Another case-control study ${ }^{57}$ showed that topical NSAIDs might decrease the risk of squamous cell carcinoma (ever use vs non-use, incidence rate ratio (IRR): $0.85,0.76$ to 0.94 ) and malignant melanoma (IRR: $0.87,0.80$ to 0.95 ). Finally, no AEs associated with topical NSAIDs were reported in the cross-sectional study. ${ }^{58}$

\section{DISCUSSION}

This is the first network meta-analysis to take into account all available evidence from RCTs directly or indirectly comparing topical NSAIDs in OA, thereby increasing the power of the study. For example, although there were only two trials for diclofenac patch (diclofenac patch vs placebo), there were 13 indirect comparisons (32 trials) through the network. The present study is also the first to summarise both RCTs and observational studies regarding the safety of topical NSAIDs. The main findings are: (1) topical NSAIDs are effective for the treatment of OA; (2) apart from topical salicylate acid, topical NSAIDs are not associated with serious GI and renal adverse events; (3) diclofenac patch is the most effective topical NSAIDs for pain relief, whereas topical piroxicam is the most effective topical NSAIDs for functional improvement.

Our previous conventional meta-analysis (13 RCTs) suggested that the efficacy of topical NSAIDs in OA only remained significant in the first 2 weeks compared with placebo. ${ }^{28}$ According to the NICE OA Guidelines 2014, both effect estimate and the related $95 \% \mathrm{CI}$ need to be greater than $0.5 \mathrm{SD}$, corresponding to a $1.2 \mathrm{~cm}$ decrease on a $10 \mathrm{~cm}$ visual analogue scale, which was considered to be the minimal clinically important difference (MCID)..$^{5}$ Although the present conventional meta-analysis (36 RCTs) further confirms the time-dependent effects of topical 


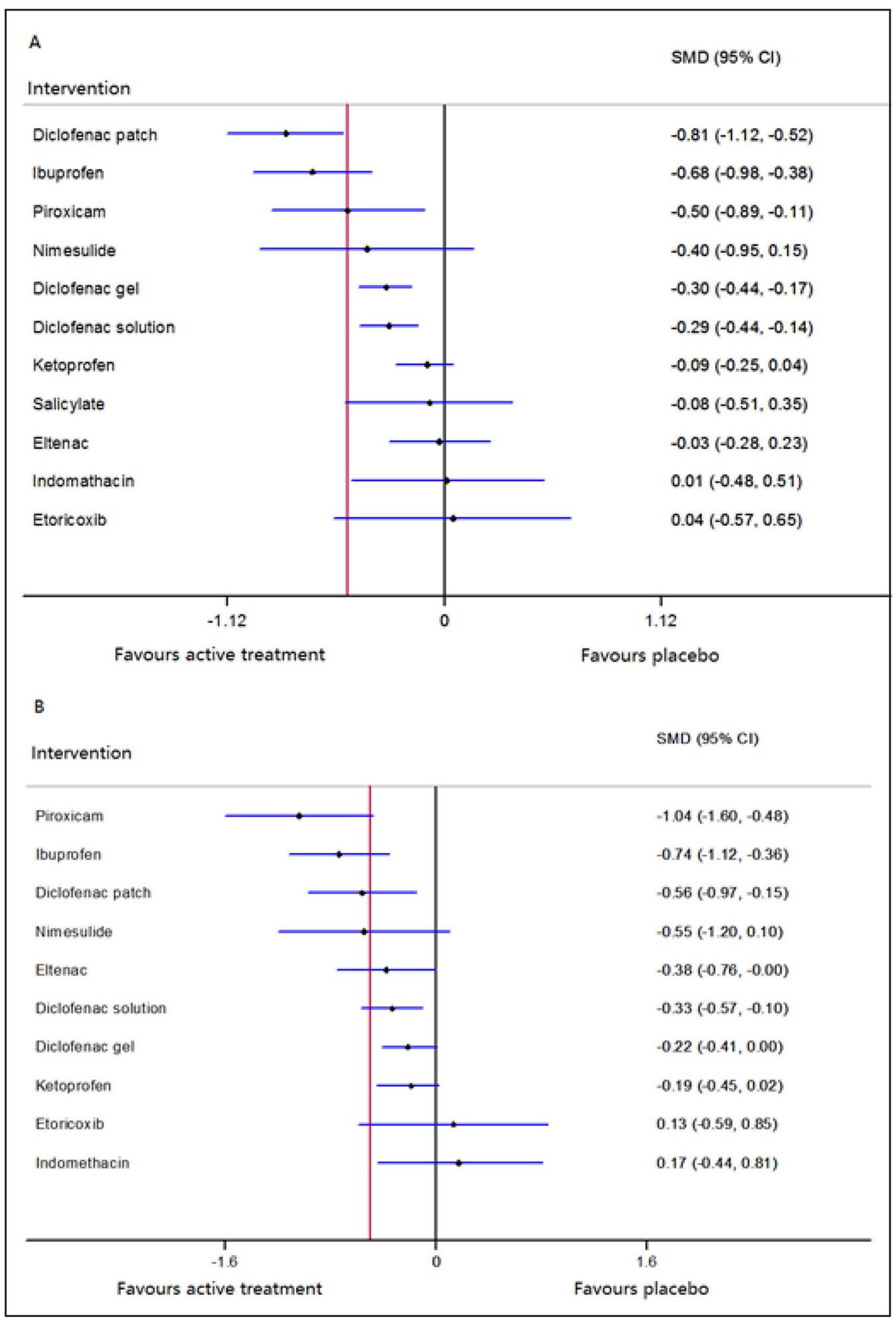

Figure 3 (A) Network meta-analysis of pain relief for different active interventions compared with placebo in randomised controlled trials. The number of trials and number of participants (pts) involved in the direct comparisons (vs placebo) were: diclofenac patch (two trials, 245 pts), ibuprofen (three trials, 214 pts), piroxicam (one trial, 179 pts), nimesulide (one trial, 70 pts), diclofenac gel (seven trials, 1776 pts), diclofenac solution (five trials, 1272 pts), ketoprofen (five trials, 2614 pts), salicylate (one trial, 114 pts), eltenac (two trials, 437 pts), indomethacin (none) and etoricoxib (one trial, $48 \mathrm{pts}$ ), and the number of trials and number of participants involved in the indirect comparisons were: diclofenac gel versus indomethacin (one trial, 98 pts). (B) Network meta-analysis of treatment effects on functional improvement for different active interventions compared with placebo. The number of trials and number of participants (pts) involved in the direct comparisons (vs placebo) were: piroxicam (one trial, 179 pts), ibuprofen (three trials, 211 pts), diclofenac patch (two trials, 245 pts), nimesulide (one trial, 70 pts), eltenac (two trials, 437 pts), diclofenac solution (five trials, 1272 pts), diclofenac gel (six trials, 1657 pts), ketoprofen (four trials, 2583 pts), etoricoxib (one trial, 48 pts) and indomethacin (none). The number of trials and number of participants involved in the indirect comparisons was: diclofenac gel versus indomethacin (one trial, 98 pts) and diclofenac gel versus ketoprofen (one trial, 85 pts). SMD, standardised mean difference. 


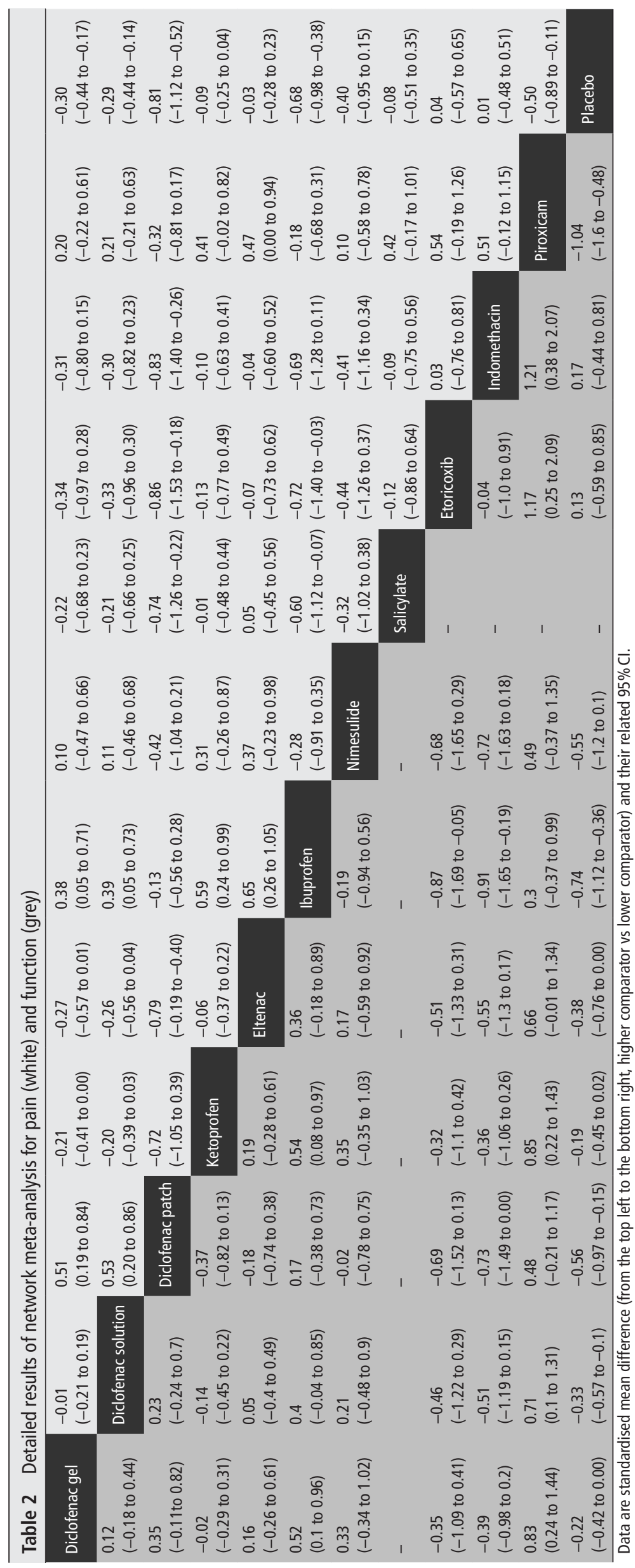


Table 3 Adverse effects of different topical NSAIDs compared with placebo according to network meta-analysis in RCTs

\begin{tabular}{|c|c|c|}
\hline Treatment & OR $(95 \% \mathrm{Cl})$ & SUCRA (\%) \\
\hline \multicolumn{3}{|l|}{ Skin AE } \\
\hline Placebo & Reference & 62.0 \\
\hline Diclofenac gel & 1.58 (0.58 to 4.87$)$ & 39.8 \\
\hline Diclofenac solution & 1.78 (0.79 to 4.08$)$ & 34.1 \\
\hline Diclofenac patch & 0.94 (0.11 to 7.11$)$ & 57.6 \\
\hline Ketoprofen & 1.17 (0.48 to 2.96$)$ & 52.8 \\
\hline Eltenac & 1.19 (0.20 to 6.57$)$ & 51.0 \\
\hline Ibuprofen & 0.93 (0.02 to 62.38$)$ & 54.4 \\
\hline Nimesulide & $1.14(0.05$ to 58.10$)$ & 50.5 \\
\hline Salicylate & 5.34 (0.68 to 43.38$)$ & 12.8 \\
\hline Piroxicam & $1.49(0.34$ to 7.11$)$ & 43.2 \\
\hline Indomethacin & 0.07 (0.00 to 2.37 ) & 92.0 \\
\hline \multicolumn{3}{|l|}{ GI AE } \\
\hline Placebo & Reference & 45.3 \\
\hline Diclofenac gel & 1.25 (0.52 to 2.59$)$ & 30.1 \\
\hline Diclofenac solution & 0.99 (0.54 to 1.86$)$ & 46.3 \\
\hline Diclofenac patch & 0.99 (0.06 to 23.14$)$ & 47.9 \\
\hline Ketoprofen & $0.82(0.41$ to 1.64$)$ & 62.2 \\
\hline Eltenac & 0.62 (0.14 to 2.86 ) & 69.6 \\
\hline Salicylate & 0.97 (0.21 to 4.54$)$ & 48.5 \\
\hline \multicolumn{3}{|l|}{ Withdrawal due to $\mathrm{AE}$} \\
\hline Placebo & Reference & 78.0 \\
\hline Diclofenac gel & 1.93 (0.94 to 3.91$)$ & 38.8 \\
\hline Diclofenac solution & 1.43 (0.73 to 2.86$)$ & 54.2 \\
\hline Diclofenac patch & 0.47 (0.03 to 3.70$)$ & 85.9 \\
\hline Ketoprofen gel & 1.40 (0.80 to 2.55$)$ & 54.8 \\
\hline Eltenac gel & 1.27 (0.11 to 35.04$)$ & 57.3 \\
\hline Salicylate gel & 16.83 (2.12 to 499.3$)$ & 37.5 \\
\hline Indomethacin & 3.22 (0.63 to 17.43$)$ & 27.2 \\
\hline
\end{tabular}

$\mathrm{AE}$, adverse effect; $\mathrm{Gl}$, gastrointestinal; RCTs, randomised controlled trials; SUCRA, surface under the cumulative ranking.

NSAIDs, they did not reach the MCID at any time-point (online supplementary appendix 5). A similar pattern was also observed for functional improvement (online supplementary appendix 5). However, care must be taken in the interpretation of this result, as the studies pooled at each time point were different. This may partially explain why there were some fluctuations/variations. Further studies to examine the wear-off effect of topical NSAIDs for analgesia and functional improvement in OA are still warranted.

Previous systematic reviews have indicated that the overall effect size of topical NSAIDs in the treatment of knee or hip OA is 0.44 (95\% CI 0.27 to 0.62 ) for pain relief. ${ }^{28}{ }^{59-62}$ However, the present study showed a smaller effect size $(0.30,95 \%$ CI 0.20 to 0.40 ), which may be explained by the recent publication of more high quality RCTs. The most novel finding is that diclofenac patch exhibited the largest effect on pain, even above that of diclofenac gel and solution. This may be due to the constant and continuous delivery of the active ingredient to the affected area by means of an occlusive bandage and slow release of the drug when compared with traditional topical formulations such as gel and solution. ${ }^{63}{ }^{64}$ It may also be due to the higher contextual effects of patches than creams/gels. ${ }^{29}{ }^{65}$ Due to the limited number of trials for other topical NSAIDs, we were unable to examine the different formulations for each topical NSAID. Thus more work needs to be done to confirm whether the patch formulation is indeed better than other formulations and what makes it better. Another possible explanation may be the shorter follow-up duration of diclofenac patch studies, as evidence suggests that the effects of topical NSAIDs may be gradually weakened with the passage of time. ${ }^{28}$ However, a subgroup analysis conducted by restricting to trials with efficacy data at 1 or 2 weeks for all topical NSAIDs showed that diclofenac patch still exhibited the largest effect.

For the overall safety of topical NSAIDs, only RCT evidence has been systematically reviewed previously. ${ }^{28} 59$ Although some individual RCTs have indicated higher skin reactions in topical NSAIDs than in placebo, this study did not confirm this. This may be due to the larger sample size lowering the likelihood of 'small study effects'. Another possible explanation is that a higher incidence of skin AEs may be attributed to specific topical NSAIDs (eg, diclofenac solution, diclofenac gel and salicylate gel). ${ }^{60-62 ~ 66-69}$ Furthermore, there were two trials with significantly higher skin reactions in placebo groups than in active groups, ${ }^{7071}$ which may offset the effect of topical NSAIDs. It should be noted that one of the studies used hyaluronan gel as the placebo group. ${ }^{70}$ The present study also found that topical NSAIDs overall exhibited a higher withdrawal rate due to AEs than the placebo group $(\mathrm{OR}=1.56)$. After excluding the trials with salicylate gel, which were associated with higher withdrawals due to AEs, we still observed a significant, but smaller $\mathrm{AE}$ risk $(\mathrm{OR}=1.47,95 \% \mathrm{CI} 1.15$ to 1.90).

A recent network meta-analysis that compared seven different oral NSAIDs for the treatment of OA found that diclofenac $150 \mathrm{mg} /$ day was the most effective for pain and function. ${ }^{72}$ Several RCTs have confirmed that the clinical efficacy of topical diclofenac or ibuprofen is comparable with their corresponding oral forms, but with better tolerability and safety, which support the use of topical NSAIDs ahead of their oral counterparts. ${ }^{68}{ }^{73-76}$ In addition, the superior safety of topical NSAIDs in terms of GI, CV and renal risks has also been shown in the general population when compared with oral NSAIDs. ${ }^{52} 5377$ On the basis of our findings, topical NSAIDs can be readily prescribed for the treatment of OA irrespective of common comorbidities or other medications. The choice of topical NSAID may be made according to the order presented in figure 3 . The order should be based on both the SMD and its 95\% CI and diclofenac patch is, therefore, the first line topical NSAID.

There are several caveats to this study. First, the number of RCTs for some topical NSAIDs is relatively small, especially in hand OA. Second, although the present study indicated that overall topical NSAIDs were effective and safe for OA, diclofenac patch was the most effective and only topical NSAID to reach the MCID in pain relief. Third, most of the follow-up periods of the included studies were relatively short, only examined the short (1-6 weeks) and medium-term (6-12 weeks) efficacy and safety of topical NSAIDs in RCTs. This is problematic for safety profiles as it is not possible to measure long-term outcomes for drug safety, such as GI and CV events. We, therefore, included the observational studies to overcome this limitation. Fourth, we only identified seven observational studies (218 074 participants) for the assessment of the safety of topical NSAIDs in the real world setting, irrespective of the target condition. A population-based and well-controlled cohort study is still needed to confidently determine a causal relationship between topical NSAIDs and AEs, especially CV AEs in people with OA. Fifth, like other meta-analyses, heterogeneity may affect the results of this meta-analysis. Last but not least, after excluding industry-funded/sponsored trials, 
What is already known on this topic?

- Topical non-steroidal anti-inflammatory drugs (NSAIDs) are recommended for the treatment of osteoarthritis by many guidelines.

- There are a number of topical NSAIDs. However, their relative efficacy remains largely unknown because there are few head-to-head comparative trials.

- The safety of topical NSAIDs remains unclear, especially its systemic side effects such as gastrointestinal and cardiovascular events.

\section{What are the new findings?}

- Topical non-steroidal anti-inflammatory drugs (NSAIDs) are effective to reduce pain and improve function in osteoarthritis.

- Among all available topical NSAIDs, diclofenac patches were most effective for pain relief and piroxicam was the best option to improve function.

- Other than salicylate gel, topical NSAIDs are safe. They are not associated with increased local or systemic adverse effects such as gastrointestinal and renal events; this can be concluded from both randomised trials and observational studies.

only diclofenac patch was statistically superior to placebo for pain relief and none of the topical NSAIDs was better than placebo for functional improvement. This suggests that the efficacy of topical NSAIDs may be inflated by industry involvement. However, the limited number of remaining non-industry-funded/sponsored trials (only 12 trials for pain relief and 11 trials for functional improvement) may be too small to detect the difference, as these trials were small (ranging from 31 to 179 participants, median size 100). Further non-industry-funded/sponsored trials for topical NSAIDs are still needed, as this is a group of drugs with greater contextual effect than their oral counterparts ${ }^{29}$ and it is more difficult to blind participants in trials and hence very easy to inflate their treatment benefits over placebo. We also attempted to examine whether trials with $\geq 100$ participants per arm would give a different conclusion but failed as only 13 trials which fulfilled this criterion.

\section{CONCLUSION}

This systematic review identified 43 studies, comparing 36 RCTs (7900 patients with OA at any joint) and 7 observational studies (218 074 participants). Topical NSAIDs reduced pain and improved function in patients with OA. Diclofenac patches were the most effective topical NSAID for pain relief. No serious AEs were observed in randomised trials or observational studies in the general population. However, confirmation of the CV safety of topical NSAIDs still warrants further observational study.

\section{Author affiliations}

'Department of Orthopaedics, Xiangya Hospital, Central South University, Changsha, Hunan, China

${ }^{2}$ Division of Rheumatology, Allergy and Immunology, Department of Medicine, Massachusetts General Hospital, Harvard Medical School, Boston, Massachusetts, USA
${ }^{3}$ Health Management Center, Xiangya Hospital, Central South University, Changsha, China

${ }^{4}$ Academic Rheumatology, Clinical Sciences Building, University of Nottingham, City Hospital, Nottingham, UK

${ }^{5}$ Arthritis Research UK Pain Centre, Nottingham, UK

${ }^{6}$ Hunan Key Laboratory of Joint Degeneration and Injury, Changsha, Hunan, China ${ }^{7}$ National Clinical Research Center of Geriatric Disorders, Xiangya Hospital, Central South University, Changsha, Hunan, China

${ }^{8}$ Center for Clinical Technology and Research of Joint Surgery, Hunan, China

Acknowledgements The authors thank Sofia Dias (School of Social and Community Medicine, University of Bristol) for her correction in code; Tony Ades, Sofia Dias, Nicky Welton, Debbi Caldwell (School of Social and Community Medicine, University of Bristol) and Kieth Abrams, Alex Sutton, Nicola Cooper (Department of Health Sciences, University of Leicester, University of Leicester) for their course 'Indirect and Mixed Treatment Comparisons, 2015'. The authors appreciate the support of Orthopedics Research Institute of Xiangya Hospital. We wish to thank Ms Michelle Zhang for proof reading the manuscript.

Contributors GL, WZ, CZ and JW had full access to all the data in the study and take responsibility for the integrity of the data and the accuracy of the data analysis. Concept and design: GL, WZ, CZ. Acquisition, analysis or interpretation of data: all authors. Drafting of the manuscript: $C Z$, JW. Critical revision of the manuscript for important intellectual content: WZ, GL, MSMP, MD, AS. Statistical analysis: JW, XL. Study supervision: GL, WZ.

Funding This work was supported by the National Natural Science Foundation of China $(81472130,81672225,81601941,81501923,81772413,81702207$, 81702206), the Postdoctoral Science Foundation of Central South University (182130), the Young Investigator Grant of Xiangya Hospital, Central South University (2016Q03, 2016Q06), the Scientific Research Project of the Development and Reform Commission of Hunan Province ([2013]1199), the Scientific Research Project of Science and Technology Office of Hunan Province (2013SK2018), the Key Research and Development Program of Hunan Province (2016JC2038), the Xiangya Clinical Big Data System Construction Project of Central South University (45), the Clinical Scientific Research Foundation of Xiangya Hospital, Central South University (2015L03), the Fundamental Research Funds for the Central Universities of Central South University (2015zzts112) and the Natural Science Foundation of Hunan Province (2017JJ3491, 2017JJ3492).

Competing interests None declared.

Provenance and peer review Not commissioned; externally peer reviewed.

Open Access This is an Open Access article distributed in accordance with the Creative Commons Attribution Non Commercial (CC BY-NC 4.0) license, which permits others to distribute, remix, adapt, build upon this work non-commercially, and license their derivative works on different terms, provided the original work is properly cited and the use is non-commercial. See: http://creativecommons.org/ licenses/by-nc/4.0/

(c) Article author(s) (or their employer(s) unless otherwise stated in the text of the article) 2018. All rights reserved. No commercial use is permitted unless otherwise expressly granted.

\section{REFERENCES}

1 Glyn-Jones S, Palmer AJR, Agricola R, et al. Osteoarthritis. The Lancet 2015;386:376-87.

2 Drawer $S$, Fuller CW. Propensity for osteoarthritis and lower limb joint pain in retired professional soccer players. Br J Sports Med 2001;35:402-8.

3 Turner AP, Barlow JH, Heathcote-Elliott C. Long term health impact of playing professional football in the United Kingdom. Br J Sports Med 2000;34:332-6.

4 Lequesne MG, Dang N, Lane NE. Sport practice and osteoarthritis of the limbs. Osteoarthritis Cartilage 1997;5:75-86.

5 NICE. The care and management of adults with OA. In: National Institute of Health and Clinical Excellence. 2014. https://www.nice.org.uk/guidance/CG59

6 McAlindon TE, Bannuru RR, Sullivan MC, et al. OARSI guidelines for the non-surgical management of knee osteoarthritis. Osteoarthr Cartilage 2014;22:363-88.

7 Brown GA. AAOS clinical practice guideline: treatment of osteoarthritis of the knee: evidence-based guideline, 2nd edition. J Am Acad Orthop Surg 2013;21:577-9.

8 Hochberg MC, Altman RD, April KT, et al. American College of Rheumatology 2012 recommendations for the use of nonpharmacologic and pharmacologic therapies in osteoarthritis of the hand, hip, and knee. Arthrit Care Res 2012;64:465-74.

9 Nelson AE, Allen KD, Golightly YM, et al. A systematic review of recommendations and guidelines for the management of osteoarthritis: The Chronic Osteoarthritis Management Initiative of the U. S. Bone and Joint Initiative. Semin Arthritis Rheu 2014;43:701-12

10 Zhang W, Doherty M, Leeb BF, et al. EULAR evidence based recommendations for the management of hand osteoarthritis: report of a Task Force of the EULAR Standing Committee for International Clinical Studies Including Therapeutics (ESCISIT). Ann Rheum Dis 2007;66:377-88 
11 Bannuru RR, Schmid CH, Kent DM, et al. Comparative effectiveness of pharmacologic interventions for knee osteoarthritis: a systematic review and network meta-analysis. Ann Intern Med 2015;162:46-54.

12 Scarpignato C, Lanas A, Blandizzi C, et al. Safe prescribing of non-steroidal antiinflammatory drugs in patients with osteoarthritis--an expert consensus addressing benefits as well as gastrointestinal and cardiovascular risks. BMC Med 2015;13:55.

13 Helin-Salmivaara A, Virtanen A, Vesalainen R, et al. NSAID use and the risk of hospitalization for first myocardial infarction in the general population: a nationwide case-control study from Finland. Eur Heart J 2006;27:1657-63.

14 Laine L, White WB, Rostom A, et al. COX-2 selective inhibitors in the treatment of osteoarthritis. Semin Arthritis Rheum 2008;38:165-87.

15 Zeng C, Wei J, Li H, et al. Comparison between $200 \mathrm{mg}$ QD and $100 \mathrm{mg}$ BID oral celecoxib in the treatment of knee or hip osteoarthritis. Sci Rep-UK 2015:5:10593.

16 Zeng C, Wei J, Li H, et al. Effectiveness and safety of Glucosamine, chondroitin, the two in combination, or celecoxib in the treatment of osteoarthritis of the knee. Sci Rep-UK 2015;5:16827

17 McGettigan P, Henry D. Use of non-steroidal anti-inflammatory drugs that elevate cardiovascular risk: an examination of sales and essential medicines lists in low-, middle-, and high-income countries. PLoS Med 2013;10:e1001388.

18 Ray WA, Chung CP, Stein CM, et al. Risk of peptic ulcer hospitalizations in users of NSAIDs with gastroprotective cotherapy versus coxibs. Gastroenterology 2007;133:790-8.

19 Chan FK, Lanas A, Scheiman J, et al. Celecoxib versus omeprazole and diclofenac in patients with osteoarthritis and rheumatoid arthritis (CONDOR): a randomised trial. Lancet 2010;376:173-9.

20 Burmester G, Lanas A, Biasucci L, et al. The appropriate use of non-steroidal antiinflammatory drugs in rheumatic disease: opinions of a multidisciplinary European expert panel. Ann Rheum Dis 2011;70:818-22.

21 Chen YF, Jobanputra P, Barton P, et al. Cyclooxygenase-2 selective non-steroidal antiinflammatory drugs (etodolac, meloxicam, celecoxib, rofecoxib, etoricoxib, valdecoxib and lumiracoxib) for osteoarthritis and rheumatoid arthritis: a systematic review and economic evaluation. Health Technol Assess 2008;12:1-278.

22 Simon LS. Nonsteroidal anti-inflammatory drugs and their risk: a story still in development. Arthritis Res Ther 2013;15(Suppl 3):S1.

23 Heyneman CA, Lawless-Liday C, Wall GC. Oral versus topical NSAIDs in rheumatic diseases: a comparison. Drugs 2000;60:555-74

24 Makris UE, Kohler MJ, Fraenkel L. Adverse effects of topical nonsteroida antiinflammatory drugs in older adults with osteoarthritis: a systematic literature review. J Rheumatol 2010:37:1236-43.

25 Andrews PA, Sampson SA. Topical non-steroidal drugs are systemically absorbed and may cause renal disease. Nephrol Dial Transplant 1999:14:187-9.

26 Sitenga GL, Ing EB, Van Dellen RG, et al. Asthma caused by topical application of ketorolac. Ophthalmology 1996;103:890-2.

27 Vaile JH, Davis P. Topical NSAIDs for musculoskeletal conditions. A review of the literature. Drugs 1998;56:783-99.

28 Lin J, Zhang W, Jones A, et al. Efficacy of topical non-steroidal anti-inflammatory drugs in the treatment of osteoarthritis: meta-analysis of randomised controlled trials. BMJ 2004;329:324

29 Zou K, Wong J, Abdullah N, et al. Examination of overall treatment effect and the proportion attributable to contextual effect in osteoarthritis: meta-analysis of randomised controlled trials. Ann Rheum Dis 2016;75:1964-70.

30 Derry S, Conaghan P, Da Silva JA, et al. Topical NSAIDs for chronic musculoskeletal pain in adults. Cochrane Database Syst Rev 2016;4:D7400.

31 Higgins JPT, Green S. Cochrane Handbook for Systematic Reviews of Interventions Version 5.1.0. London, UK: The Cochrane Collaboration, 2011. http://www.cochranehandbook.org

32 Wells GA, Shea B, O'Connell D, et al. The Newcastle-Ottawa Scale (NOS) for assessing the quality of nonrandomised studies in meta-analyses. 2000.

33 Jüni P, Reichenbach S, Dieppe P. Osteoarthritis: rational approach to treating the individual. Best Pract Res Clin Rheumato/ 2006;20:721-40.

34 Zeng C, Li H, Yang T, et al. Effectiveness of continuous and pulsed ultrasound for the management of knee osteoarthritis: a systematic review and network meta-analysis. Osteoarthritis Cartilage 2014:22:1090-9.

35 Zeng C, Li H, Yang T, et al. Electrical stimulation for pain relief in knee osteoarthritis: systematic review and network meta-analysis. Osteoarthritis Cartilage 2015;23:189-202

36 Caldwell DM, Ades AE, Higgins JP. Simultaneous comparison of multiple treatments: combining direct and indirect evidence. BMJ 2005;331:897-900.

37 Caldwell DM, Welton NJ, Ades AE. Mixed treatment comparison analysis provides internally coherent treatment effect estimates based on overviews of reviews and can reveal inconsistency. J Clin Epidemiol 2010;63:875-82.

38 Lumley T. Network meta-analysis for indirect treatment comparisons. Stat Med 2002;21:2313-24

39 Lu G, Ades AE. Combination of direct and indirect evidence in mixed treatment comparisons. Stat Med 2004:23:3105-24.

40 Bucher HC, Guyatt GH, Griffith LE, et al. The results of direct and indirect treatment comparisons in meta-analysis of randomized controlled trials. J Clin Epidemiol 1997;50:683-91.
41 Trelle $\mathrm{S}$, Reichenbach S, Wandel $\mathrm{S}$, et al. Cardiovascular safety of non-steroidal antiinflammatory drugs: network meta-analysis. BMJ 2011;342:C7086.

42 Wu HY, Huang JW, Lin HJ, et al. Comparative effectiveness of renin-angiotensin system blockers and other antihypertensive drugs in patients with diabetes: systematic review and bayesian network meta-analysis. BMJ 2013;347:f6008.

43 Navarese EP, Tandjung K, Claessen B, et al. Safety and efficacy outcomes of first and second generation durable polymer drug eluting stents and biodegradable polymer biolimus eluting stents in clinical practice: comprehensive network meta-analysis. $B M J$ 2013;347:f6530.

44 Chaimani A, Higgins JP, Mavridis D, et al. Graphical tools for network meta-analysis in STATA. PLoS One 2013;8:e76654.

45 Dias S, Welton NJ, Caldwell DM, et al. Checking consistency in mixed treatment comparison meta-analysis. Stat Med 2010;29:932-44.

46 Salanti G, Ades AE, loannidis JP. Graphical methods and numerical summaries for presenting results from multiple-treatment meta-analysis: an overview and tutorial. J Clin Epidemiol 2011;64:163-71.

47 Dias S, Sutton AJ, Welton NJ, et al. Evidence synthesis for decision making 3: heterogeneity--subgroups, meta-regression, bias, and bias-adjustment. Med Decis Making 2013:33:618-40.

48 Skapinakis P, Caldwell DM, Hollingworth W, et al. Pharmacological and psychotherapeutic interventions for management of obsessive-compulsive disorder in adults: a systematic review and network meta-analysis. Lancet Psychiatry 2016:3:730-9

49 Salanti G, Marinho V, Higgins JP. A case study of multiple-treatments metaanalysis demonstrates that covariates should be considered. J Clin Epidemiol 2009:62:857-64

50 Altman RD, Dreiser RL, Fisher CL, et al. Diclofenac sodium gel in patients with primary hand osteoarthritis: a randomized, double-blind, placebo-controlled trial. J Rheumatol 2009;36:1991-9.

51 Kneer W, Rother M, Mazgareanu S, et al. A 12-week randomized study of topical therapy with three dosages of ketoprofen in Transfersome ${ }^{\circledR}$ gel (IDEA-033) compared with the ketoprofen-free vehicle (TDT 064), in patients with osteoarthritis of the knee. J Pain Res 2013:6:743.

52 Evans JM, McMahon AD, McGilchrist MM, et al. Topical non-steroidal antiinflammatory drugs and admission to hospital for upper gastrointestinal bleeding and perforation: a record linkage case-control study. BMJ 1995;311:22-6.

53 Evans JM, McGregor E, McMahon AD, et al. Non-steroidal anti-inflammatory drugs and hospitalization for acute renal failure. QJM 1995;88:551-7.

54 García Rodríguez LA, Hernández-Díaz S. Risk of uncomplicated peptic ulcer among users of aspirin and nonaspirin nonsteroidal antiinflammatory drugs. Am J Epidemiol 2004;159:23-31.

55 Diaz RL, Gardeazabal J, Manrique P, et al. Greater allergenicity of topical ketoprofen in contact dermatitis confirmed by use. Contact Dermatitis 2006;54:239-43.

56 Cazzaniga S, Naldi L, Lecchi S, et al. A pilot study on the incidence of severe photosensitivity reactions leading to hospitalization linked to topical ketoprofen and other medications in selected European regions. Pharmacol Res Perspect 2016; $4:$ :e225

57 Johannesdottir SA, Chang ET, Mehnert F, et al. Nonsteroidal anti-inflammatory drugs and the risk of skin cancer: a population-based case-control study. Cancer 2012;118:4768-76.

58 Yagüe-Sebastián MM, Coscollar-Escartín I, Muñoz-Albadalejo P, et al. Uso de antiinflamatorios tópicos en un centro de salud urbano. Estudio comparativo con la evidencia actual [Use of topical non-steroidal anti-inflammatory agents in an urban health center. Comparison with the current evidence]. SEMERGEN - Medicina de Familia 2013:39:304-8

59 Zhang W, Nuki G, Moskowitz RW, et al. OARSI recommendations for the management of hip and knee osteoarthritis: part III: Changes in evidence following systematic cumulative update of research published through January 2009. Osteoarthritis Cartilage 2010;18:476-99.

60 Baer PA, Thomas LM, Shainhouse Z. Treatment of osteoarthritis of the knee with a topical diclofenac solution: a randomised controlled, 6-week trial [ISRCTN53366886]. BMC Musculoskelet Disord 2005;6:44

61 Bookman AA, Williams KS, Shainhouse JZ. Effect of a topical diclofenac solution for relieving symptoms of primary osteoarthritis of the knee: a randomized controlled trial. CMAJ 2004;171:333-8

62 Roth SH, Shainhouse JZ. Efficacy and safety of a topical diclofenac solution (pennsaid) in the treatment of primary osteoarthritis of the knee: a randomized, double-blind, vehicle-controlled clinical trial. Arch Intern Med 2004;164:2017-23.

63 Gallacchi G, Marcolongo R. Pharmacokinetics of diclofenac hydroxyethylpyrrolidine (DHEP) plasters in patients with monolateral knee joint effusion. Drugs Exp Clin Res 1993;19:95-7

64 Assandri A, Canali S, Giachetti C. Local tolerability and pharmacokinetic profile of a new transdermal delivery system, diclofenac hydroxyethylpyrrolidine plaster. Drugs Exp Clin Res 1993;19:89-95.

65 Zhang W, Robertson J, Jones AC, et al. The placebo effect and its determinants in osteoarthritis: meta-analysis of randomised controlled trials. Ann Rheum Dis 2008:67:1716-23.

66 Unpublished data from Cochrane Library. http://www.cochrane.org 
67 Baraf HS, Gold MS, Clark MB, et al. Safety and efficacy of topical diclofenac sodium $1 \%$ gel in knee osteoarthritis: a randomized controlled trial. Phys Sportsmed 2010;38:19-28.

68 Shackel NA, Day RO, Kellett B, et al. Copper-salicylate gel for pain relief in osteoarthritis: a randomised controlled trial. Med J Aust 1997:167:134-6.

69 Simon LS, Grierson LM, Naseer Z, et al. Efficacy and safety of topical diclofenac containing dimethyl sulfoxide (DMSO) compared with those of topical placebo, DMSO vehicle and oral diclofenac for knee osteoarthritis. Pain 2009:143:238-45.

70 Roth SH. A controlled clinical investigation of 3\% diclofenac/2.5\% sodium hyaluronate topical gel in the treatment of uncontrolled pain in chronic oral NSAID users with osteoarthritis. Int J Tissue React 1995;17:129-32.

71 Wadsworth LT, Kent JD, Holt RJ. Efficacy and safety of diclofenac sodium 2\% topical solution for osteoarthritis of the knee: a randomized, double-blind, vehicle-controlled, 4 week study. Curr Med Res Opin 2016;32:241-50.
72 da Costa BR, Reichenbach S, Keller N, et al. Retracted: effectiveness of non-steroidal anti-inflammatory drugs for the treatment of pain in knee and hip osteoarthritis: a network meta-analysis. Lancet 2016;387:2093-105.

73 Underwood M, Ashby D, Cross P, et al. Advice to use topical or oral ibuprofen for chronic knee pain in older people: randomised controlled trial and patient preference study. BMJ 2008;336:138-42.

74 Underwood M, Ashby D, Carnes D, et al. Topical or oral ibuprofen for chronic knee pain in older people. The TOIB study. Health Technol Assess 2008;12:155.

75 Tiso RL, Tong-Ngork S, Fredlund KL. Oral versus topical Ibuprofen for chronic knee pain: a prospective randomized pilot study. Pain Physician 2010;13:457-67.

76 Tugwell PS, Wells GA, Shainhouse JZ. Equivalence study of a topical diclofenac solution (pennsaid) compared with oral diclofenac in symptomatic treatment of osteoarthritis of the knee: a randomized controlled trial. J Rheumatol 2004;31:2002-12.

77 Lin TC, Solomon DH, Tedeschi SK, et al. Comparative risk of cardiovascular outcomes between topical and oral non-selective nsaids in taiwanese rheumatoid arthritis patients. Arthritis Rheumatol 2016;68:1839-40. 